\section{Pacific Northwest}

National Laboratory

Operated by Battelle for the

U.S. Department of Energy

\title{
Estimated Maximum Gas Retention from Uniformly Dispersed Bubbles in K Basin Sludge Stored in Large-Diameter Containers
}

\author{
P.A. Gauglitz \\ G. Terrones
}

May 2002

\footnotetext{
Prepared for the U.S. Department of Energy
} under Contract DE-AC06-76RL01830 


\title{
Estimated Maximum Gas Retention from Uniformly Dispersed Bubbles in K Basin Sludge Stored in Large-Diameter Containers
}

\author{
P. A. Gauglitz
}

G. Terrones

May 2002

Prepared for the

U.S. Department of Energy

under Contract DE-AC06-76RL01830

and the Hanford Spent Nuclear Fuel Project

Managed by Fluor Hanford, Inc.

Pacific Northwest National Laboratory

Richland, WA 99352 


\section{Executive Summary}

The KE Basin sludge that will be retrieved and stored in large-diameter containers (LDCs) contains some fraction of uranium metal that generates hydrogen gas, which introduces potential upset conditions. One postulated upset condition is that the retention of gas bubbles that are uniformly distributed causes expansion of the $\mathrm{K}$ Basin material and the material is driven into the vent filters at the top of the container. One approach to avoiding this upset condition is to limit the amount of material loaded into the LDC so that even with the maximum possible gas fraction and bed expansion the $\mathrm{K}$ Basin material would never reach the vent filter. The uniformly distributed gas bubbles are generated by metal particles that are also uniformly distributed. Uniformly distributed gas bubbles represent one limiting scenario for gas holdup and are the subject of this study. An opposite limiting scenario has gas-generating particles residing in a settled layer below a region of inert material that has no gas-generating particles. This alternative scenario potentially leads to a rising vessel-spanning "sludge plug" from the gasgenerating layer (Terrones and Gauglitz 2002).

Uranium corrosion is another mechanism for sludge bed expansion during storage. As metallic uranium and uranium oxides corrode and hydrate during storage, corrosion products are generated that have a lower particle density and higher void fraction than the starting sludge. A report was recently prepared that quantifies how the various types and sources of $\mathrm{K}$ Basin sludge will react and volumetrically expand between the time the sludge is first loaded into the LDCs and the time all major volume-changing reactions have been completed (Schmidt and Delegard 2002). The effects of sludge expansion due to both gas retention and uranium corrosion will need to be considered when establishing the final container loading parameters.

This report presents an evaluation of the retention of uniformly distributed bubbles and an estimate of the maximum gas fraction that might be retained in K Basin LDCs based on existing literature data on bubble retention and information on $\mathrm{K}$ Basin material (the maximum expansion of the sludge bed $=1 /[1-$ maximum gas fraction $]$ ). Existing data show that the maximum gas fraction varies depending on physical properties and the configuration of the material or waste. While the data show a few instances where the maximum gas fraction exceeds $35 \%$, this worst case occurs in a narrow range of physical parameters. Therefore, it is unlikely that an entire LDC would uniformly have physical properties, strength in particular, that give rise to bubble retention equal to the highest values measured in the laboratory or in some Hanford single-shell tank waste.

The maximum volume fraction that might occur in K Basin material stored in LDCs has been determined by three different approaches. The first approach was based on the assumption that maximum gas retention data on bentonite clay simulants provides a conservative representation of K Basin material. In addition, it was assumed that the LDCs had discrete layers of material with strengths randomly assigned based on all available $\mathrm{K}$ Basin measurements of yield stress. The second approach assumed two distinct regimes of bubble retention. In the lower regime, 
bubble retention was estimated from literature data on glass beadpacks; in the upper regime, bubble retention was estimated from bentonite clay data. The average gas fraction in the LDC was a combination of these two regions of retention. The third approach assumed that in situ measurements of gas retention in Hanford SST samples represent the K Basin material in LDCs.

Based on the existing data and understanding of K Basin material and the LDCs, the first approach seems most appropriate. The results show that an LDC filled with at least five randomly selected layers of $\mathrm{K}$ Basin material has a $99 \%$ probability of having maximum gas retention of less than $35 \%$, assuming the retained bubbles are uniformly distributed.

Accordingly, until testing can be conducted to support a lower estimate, this work recommends that $35 \%$ gas fraction be assumed to represent the maximum gas fraction that could be achieved in an LDC.

\section{Reference}

Schmidt AJ and $\mathrm{CH}$ Delegard. 2002. Assessment of K Basin Sludge Volume Expansion Resulting from Uranium Corrosion During Storage. PNNL-13786, Pacific Northwest National Laboratory, Richland, WA.

Terrones G and PA Gauglitz. 2002. "Vessel-Spanning Bubble Formation in K Basin Sludge Stored in Large-Diameter Containers." PNNL-13805, Pacific Northwest National Laboratory, Richland, WA. 


\section{Acknowledgements}

The authors gratefully acknowledge Andy Schmidt for his broad technical assistance and guidance. We also thank Paul Bredt and Ron Baker for helping us access pertinent video recordings and bubble images from the extensive library of $\mathrm{K}$ Basin studies spanning the past seven years. We also appreciate and acknowledge editorial contributions from Sheila Bennett. 


\section{Contents}

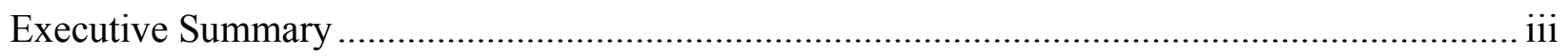

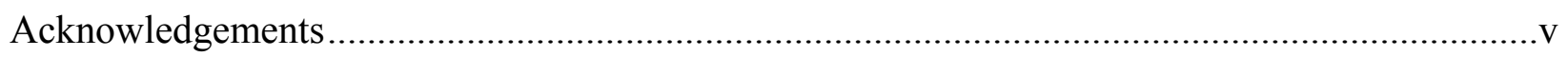

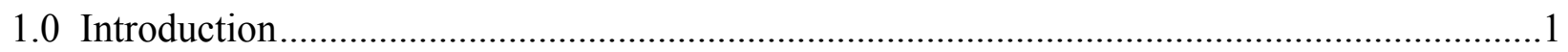

1.1 Gas-Bubble Retention Scenarios for K Basin Material in LDCs ..................................... 2

1.2 Approaches for Estimating Maximum Gas Bubble Retention ..................................... 3

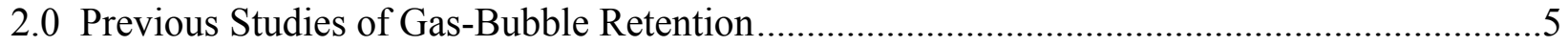

2.1 Maximum Retention for Bubbles Retained by Waste Strength .................................... 7

2.2 Maximum Retention for Bubbles Retained by Capillary Forces ................................... 8

3.0 Gas Bubble Retention Estimates for K Basin Material in LDCs ..........................................9

3.1 Maximum Retention Assuming Random Layers and the Waste Strength

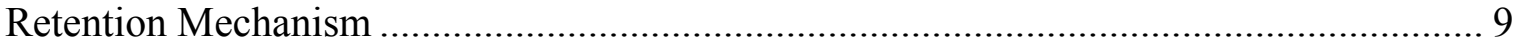

3.2 Maximum Retention Assuming Both Capillary Force and Waste Strength

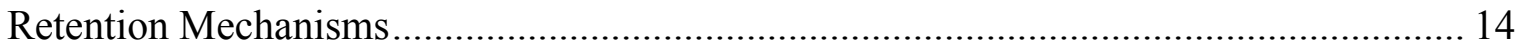

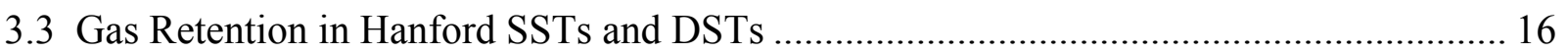

3.4 Possible Mechanisms for Lower Gas-Bubble Retention................................................ 18

4.0 Discussion and Recommendation for Maximum Gas-Bubble Retention ............................21

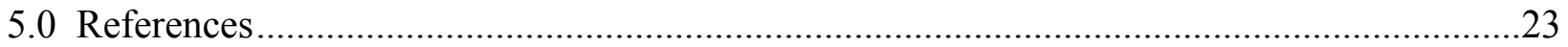




\section{Figures}

1.1 Scenarios for the Distribution of Gas-Generating Particles in LDCs .................................. 3

2.1 Bubbles Retained by Capillary Forces and by Waste Strength ........................................ 6

2.2 Maximum Gas Volume Fraction as a Function of Yield Stress for Bentonite Clay............... 7

2.3 Effect of Particle Diameter on Maximum Gas Fraction ................................................... 8

3.1 Cumulative Probability Distribution of Individual Yield Stress Measurements for K Basin Samples .......................................................................................... 11

3.2 Cumulative Probability Distribution of Maximum Gas Volume Fraction

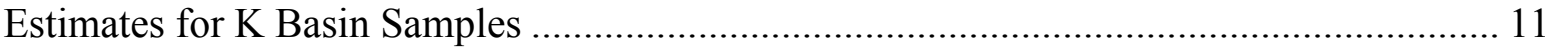

3.3 Distribution of the Maximum Gas Volume Fraction in an LDC with Five

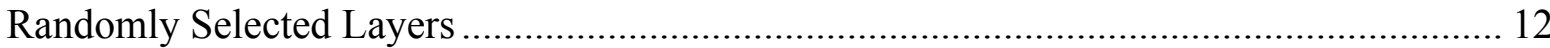

3.4 Distribution of Maximum Gas Fraction in LDC with 10 Randomly Selected Layers ......... 13

3.5 95th Percentile Gas Fraction as Function of Number of Randomly Selected Layers for

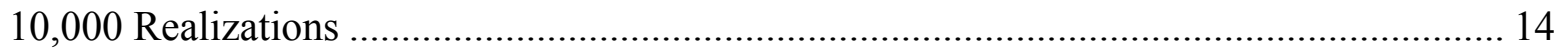

3.6 Measured Transition Depth Between Particle-Displacing and Pore-Filling Bubbles .......... 15

3.7 Comparison of Bentonite Clay Simulants with Hanford DST and SST Data for the Relationship Between Void Fraction and Yield Stress ............................................ 17

3.8 Cumulative Probability Distribution of Individual Void Fraction Measurements for Core Samples from A-101, AX-101, S-102, S-111, SX-106, U-103, and U-109 ............... 17

3.9 Observation of Bubbles in Preferential Channels for Bubble Migration............................. 19

\section{Tables}

3.1 K Basin Yield Stress Data and Maximum Gas Volume Fraction Estimates ...................... 10

3.2 K Basin Parameter Values for Estimating the Transition Depth ..................................... 15 


\subsection{Introduction}

At the U.S. Department of Energy (DOE) Hanford Site in southeastern Washington State, a considerable amount of spent nuclear fuel (SNF) is stored in two water-filled concrete pools known as the K East (KE) and K West (KW) Basins. These basins in the $100 \mathrm{~K}$ Area contain over 2100 metric tons of $\mathrm{N}$ Reactor fuel elements in aluminum or stainless steel canisters. An estimated $52 \mathrm{~m}^{3}$ of sludge have accumulated in the canisters and on the floor of the K Basins. The sludge is believed to comprise a mixture of SNF, metal corrosion products, windblown particulate material, and other constituents such as organic and inorganic ion exchange material (Makenas et al. 1996, 1997, 1998, 1999). A detailed inventory and composition description of all K Basin sludge materials can be found in Pearce (2001). According to the SNF Project objectives, the sludge will be packaged, shipped, and stored at T Plant in the Hanford 200 Area until final processing at a future date.

The KE Basin sludge will be retrieved and stored in large-diameter containers (LDCs) that are approximately $5 \mathrm{ft}$ in diameter and $10 \mathrm{ft}$ high. The material contains some fraction of uranium metal that generates hydrogen gas, introducing potential upset conditions. Gas generation within the $\mathrm{K}$ Basins has been reported and documented extensively. Oxidation of metallic uranium is responsible for generating hydrogen gas within the $\mathrm{K}$ Basin sludge (Johnson 1995; Baker et al. 2000; Bryan et al. 2001). High rates of gas generation have been observed in some K Basin sludge samples.

One postulated upset condition is that the retention of gas bubbles that are uniformly distributed causes expansion of the $\mathrm{K}$ Basin material, and the material could be driven into the vent filters at the top of the container. One approach to avoiding this upset condition is to limit the amount of material loaded into the LDC so that, even with the maximum possible bed expansion, the K Basin material would never reach the vent filter. The uniformly distributed gas bubbles are generated by metal particles that are also uniformly distributed. Uniformly distributed gas bubbles represent one limiting scenario for gas holdup and bed expansion. The subject of this report is determining of the maximum gas fraction that might be retained in LDCs filled with K Basin sludge for this scenario. The maximum gas fraction is defined as the fraction of the total bed volume occupied by gas bubbles. The maximum expansion of a sludge bed equals $1 /(1-$ maximum gas fraction $)$.

An opposite limiting situation is that of gas-generating particles residing in a settled layer below a region of inert material that has no gas-generating particles. Baker et al. (2000) have described the formation of a large pocket of gas underneath a sludge sample in an experiment with a KE sample (96-06) that had this configuration. This observation was made during the course of a series of settling rate studies. As a result of the batch sedimentation step, particulate settled, forming a stratified layer of sludge where the larger and denser particles remained at the bottom and the smaller, less dense ones at the top. This alternative scenario of vessel-spanning "sludge plugs" has been studied previously (Terrones and Gauglitz 2002). 
Uranium corrosion is another mechanism for sludge bed expansion during storage. As metallic uranium and uranium oxides corrode and hydrate during storage, corrosion products are generated that have a lower particle density and higher void fraction than the starting sludge. A report was recently prepared that quantifies how the various types and sources of $\mathrm{K}$ Basin sludge will react and volumetrically expand between the time the sludge is first loaded into the LDCs and the time all major volume-changing reactions have been completed (Schmidt and Delegard 2001). The effects of sludge expansion due to both gas retention and uranium corrosion will need to be considered when establishing the final container loading parameters.

Recent predictions of particle settling during LDC loading shows that a relatively uniform distribution of gas-generating particles occurs when multiple layers are loaded sequentially into the LDC. ${ }^{\text {(a) }}$ The ability of materials to retain uniformly distributed bubbles has been documented in several situations. One significant example is the generation and retention of gas bubbles in high-level waste stored in single- and double-shell tanks (SSTs and DSTs) at Hanford (Johnson et al. 1997, 2001). In these SSTs and DSTs, gas is retained in bubbles that are somewhat uniformly distributed. Accordingly, it is credible that the K Basin material stored in LDCs can retain uniformly distributed bubbles and thus expand. The objective of this study is to estimate the maximum gas retention that could potentially occur in an LDC.

\subsection{Gas-Bubble Retention Scenarios for K Basin Material in LDCs}

While a range of plausible LDC filling scenarios have been considered, from the viewpoint of gas bubble retention, there are two configurations that span the range of behavior. These two configurations are a homogeneous distribution of gas-generating particles and a thin layer of gasgenerating particles below a thicker layer of inert material (without gas-generating particles). If LDCs are to be filled by a series of batches from different locations at different times, a layered distribution of gas-generating particles might be expected (Figure 1.1). Once gas is generated within the sludge, it might be retained by various mechanisms that depend on the microstructure of the sludge (see Section 2).

Existing data show that the maximum gas fraction varies depending on physical properties and material configuration. While currently available data for gas retention show a few instances where the maximum gas fraction exceeds $35 \%$, this worst case occurs in a narrow range of physical parameters. Therefore, it is unlikely that an entire LDC would uniformly have physical properties, strength in particular, that give rise to bubble retention equal to the highest values measured in the Laboratory or in some Hanford SSTs.

(a) In a February 15, 2002 project memorandum, "Sludge Settling \& Segregation During Loading Draft 5," from Marty Plys of Fauske and Associates, calculations are presented for the distribution of gasgenerating particles. When multiple layers are loaded into the LDC, the distribution of particles becomes essentially uniform. 


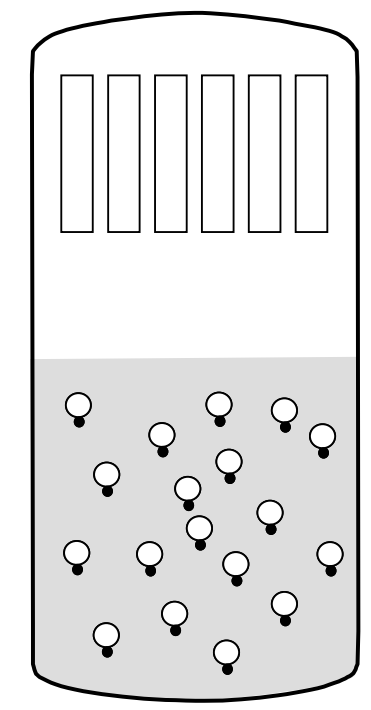

Homogeneous Distribution of Gas Generating Particles

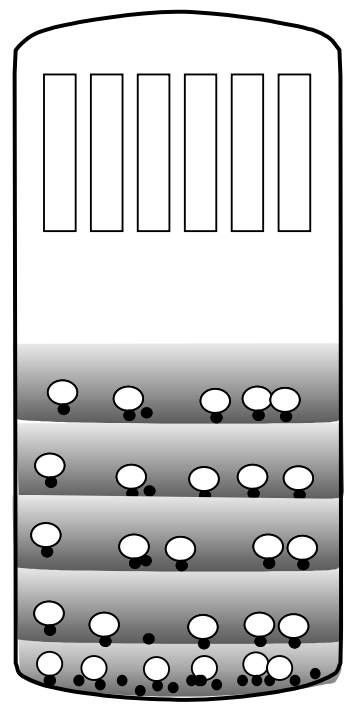

Discrete Layers of Gas Generating Particles

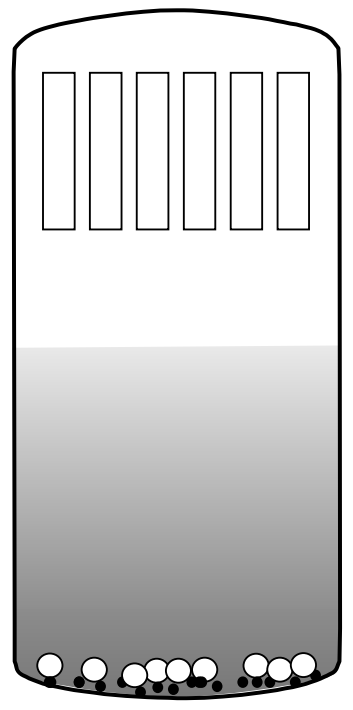

Settled Layer of Gas Generating Particles

Figure 1.1. Scenarios for the Distribution of Gas-bnGenerating Particles in LDCs

\subsection{Approaches for Estimating Maximum Gas-Bubble Retention}

The first approach is based on the assumption that the sludge in filled LDCs is arranged in five to 10 layers having the same volume but different maximum gas volume fractions. Because the degree of bubble retention in sludge depends strongly on its yield stress, the maximum gas fraction retained in $\mathrm{K}$ Basin sludge material is estimated from bubble retention data for bentonite clay simulants. Each layer is assumed to have the same gas fraction of the bed volume, so the total bed gas fraction is calculated by taking the average of the gas fractions from the randomly selected layers. Each of these random selections constitutes a statistical realization. In other words, the contents of an LDC are hypothetically filled by several layers, each of which has a maximum volume fraction randomly selected from a set of void fraction estimates for the $\mathrm{K}$ Basin sludge. Using a large number of realizations, probability distributions for the overall gas fraction in the LDC are calculated from randomly selected layers.

The second approach is based on the assumption that the most probable gas retention level for a typical K Basin sludge composite in an LDC lies somewhere between two bounding bubble retention regimes based on currently available data. In the lower regime, bubbles fill the pores between the particles, and the maximum gas retention is relatively low. In the upper regime, bubbles are capable of displacing neighboring particles, and the maximum gas retention is relatively large (determined from literature data on bentonite clay). The gas retention level for LDC sludge is estimated from a combination of these two retention regimes. 
The third approach is based on the assumption that the gas retention level for a typical $\mathrm{K}$ Basin sludge composite in an LDC is comparable to that found in Hanford DSTs and SSTs that are known to retain significant quantities of gas. 


\subsection{Previous Studies of Gas-Bubble Retention}

The generation, retention, and release of gas bubbles in high-level waste storage tanks at Hanford have been the subject of detailed studies for the past 10 years. In general, it has been found that gas retention can occur any tank that has a settled layer of wet solids, provided there is sufficient gas generation. Johnson et al. (1997, 2001) give overall summaries of the investigations for Hanford waste tanks. The retention of bubbles is not surprising and is known to occur in many materials ranging from yield stress fluids and pastes (Chhabra 1993) to ocean sediments (Wheeler 1990).

The primary measure of gas retention is the gas volume fraction in the material, which is also commonly referred to as the "void fraction." For Hanford DSTs AN-103, AN-104, AN-105, AW-101, and SY-103, which are on the Flammable Gas Watch List, the average void fraction ranged from 4 to $11 \%$ for the settled layers (Johnson et al. 2001). In these DSTs, all the individual local measurements in the settled layers were below $20 \%$ void. For SSTs on the Flammable Gas Watch List, the reported void fractions are higher (Johnson et al. 2001). Of the 26 local measurements reported for layers of wet solids, only two specific samples gave measurements higher than $35 \%$ void ( $36 \%$ in SX-106 and $42 \%$ in U-103).

The mechanisms of gas-bubble retention and bubble behavior in tank waste have been the subject of a number of studies (Gauglitz et al. 1994, 1995, 1996, 2001; Stewart et al. 1996; Rassat et al. 1997, 1998, 1999; Bredt et al. 1995; Bredt and Tingey 1996; Walker et al. 1996). In this section we present a summary of bubble retention, including data and models that can be used to predict gas bubble retention in K Basin material stored in LDCs. The principal mechanisms of bubble retention can be grouped into three categories: bubbles retained by direct attachment to particles, bubbles retained by the strength of the surrounding waste, and bubbles retained between particles by capillary forces. In layers of liquid-saturated settled solid particles called sediment, capillary forces and waste strength dominate bubble retention; direct attachment of bubbles to particles plays a minor role. The two dominant bubble retention mechanisms are discussed below.

Bubbles can be held in the interstitial spaces or pores between particles by capillary forces when the lithostatic load is sufficient to hold the particles in contact against the force of the bubble's internal pressure trying to push them apart. The lithostatic load at any elevation is given by the buoyant weight of the particles above. The capillary force retention mechanism requires either relatively large pores, which reduce the internal bubble pressure, or a deep waste column, which increases the lithostatic load, or both. These bubbles assume an irregular, dendritic shape conforming to the passages between the particles. When the internal pressure of a bubble overcomes the effect of the lithostatic load, it pushes the surrounding particles apart. The bubble is then restrained by the yield strength of the bulk waste as a particle-displacing bubble. The difference between these two types of bubbles is illustrated in Figure 2.1. 


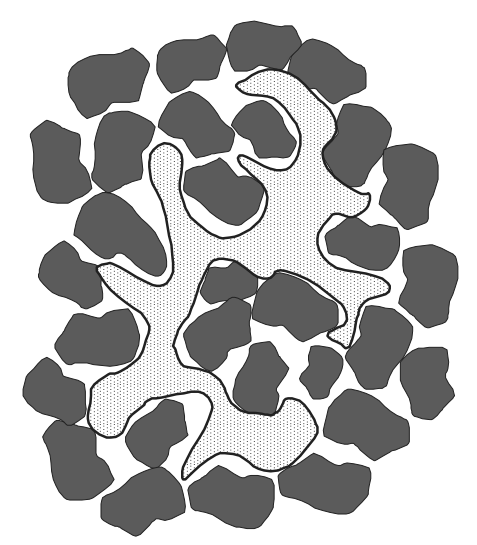

Bubble held within pores by capillary forces

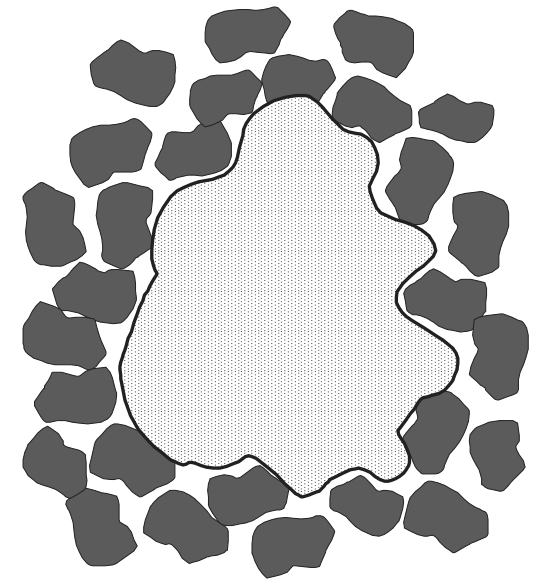

Bubble displacing particles and held by waste strength

Figure 2.1. Bubbles Retained by Capillary Forces and by Waste Strength

Whether a bubble is held by yield strength or capillary force is indicated by the Bond number criterion developed by Gauglitz et al. (1994, 1995, 1996). This dimensionless number contains two parameters, a ratio of gravitational force to surface tension force, and a ratio of waste strength force to surface tension force. If the number exceeds unity, the bubbles are in a pore-filling configuration between particles and held by capillary forces. The Bond number is expressed as

$$
\mathrm{N}_{\text {Bo }}=\frac{\Delta \rho g \mathrm{H}_{\mathrm{S}} \mathrm{D}_{\mathrm{p}}}{4 \sigma}+\frac{\tau_{\mathrm{Y}} \mathrm{D}_{\mathrm{p}}}{4 \sigma} \mathrm{A}
$$

where

$\mathrm{H}_{\mathrm{S}}$ is the height of the lithostatic column above the bubble

$\mathrm{D}_{\mathrm{P}}$ is the mean pore diameter through which a bubble must pass to escape retention; assumed to be represented by the particle diameter.

$\Delta \rho$ is the difference between bulk sediment and liquid density

$\sigma$ is the surface tension

$\tau_{Y}$ is the yield stress

$\mathrm{g}$ is the acceleration due to gravity

A is an area ratio related to how the yield stress resists bubble expansion; it was estimated to be 2.8 by Gauglitz et al. (1995) based on laboratory experiments.

As is described in the following sections, the maximum retention is different depending on whether bubbles are retained by capillary forces or yield strength. When the Bond number equals one, Equation 1 defines the transition depth, $\mathrm{H}_{\mathrm{s}}$. Knowing the transition depth for $\mathrm{K}$ Basin material in an LDC determines the appropriate maximum retention to apply to the different regions of the bed. 


\subsection{Maximum Retention for Bubbles Retained by Waste Strength}

Figure 2.2 shows the maximum gas fraction reported by Gauglitz et al. (1996) for clay simulants spanning a range of strengths and held in $2.5-\mathrm{cm}$-diameter columns. The results show that gas retention is negligible for materials of yield stress $<1 \mathrm{~Pa}$, increases to a peak value when the yield stress is about $30 \mathrm{~Pa}$, and then decreases slightly for higher values of yield stress. For the low strength range, the buoyancy of individual bubbles is sufficient to overcome the yield stress of the clay simulant. In the strength range where the retention has a peak value, the retained bubbles are roughly spherical. In this range, bubbles grow until a sufficiently high gas fraction level is achieved that the bubbles touch and coalesce and provide a pathway for gas release. At strengths above the peak in retained gas fraction, the bubbles become highly distorted slits that finger through the clay. Here, the slit-shaped bubbles coalesce and provide a gas release pathway at somewhat lower void fractions. Gauglitz et al. (1996) also report additional data showing that the maximum retention increases slightly with increasing vessel diameter from $2.5 \mathrm{~cm}$ to $90 \mathrm{~cm}$. Considering the variability in the test results, the gas volume fraction values shown in Figure 2.2 are appropriate for predicting behavior in other systems.

The data in Figure 2.2 provide a basis for estimating the maximum retention that could occur in $\mathrm{K}$ Basin material stored in an LDC. In Section 3.1, estimates are derived for the maximum gas fraction in an LDC assuming a number of discrete layers with strengths based on measurements of K Basin samples and maximum gas fractions inferred from the data in Figure 2.2.

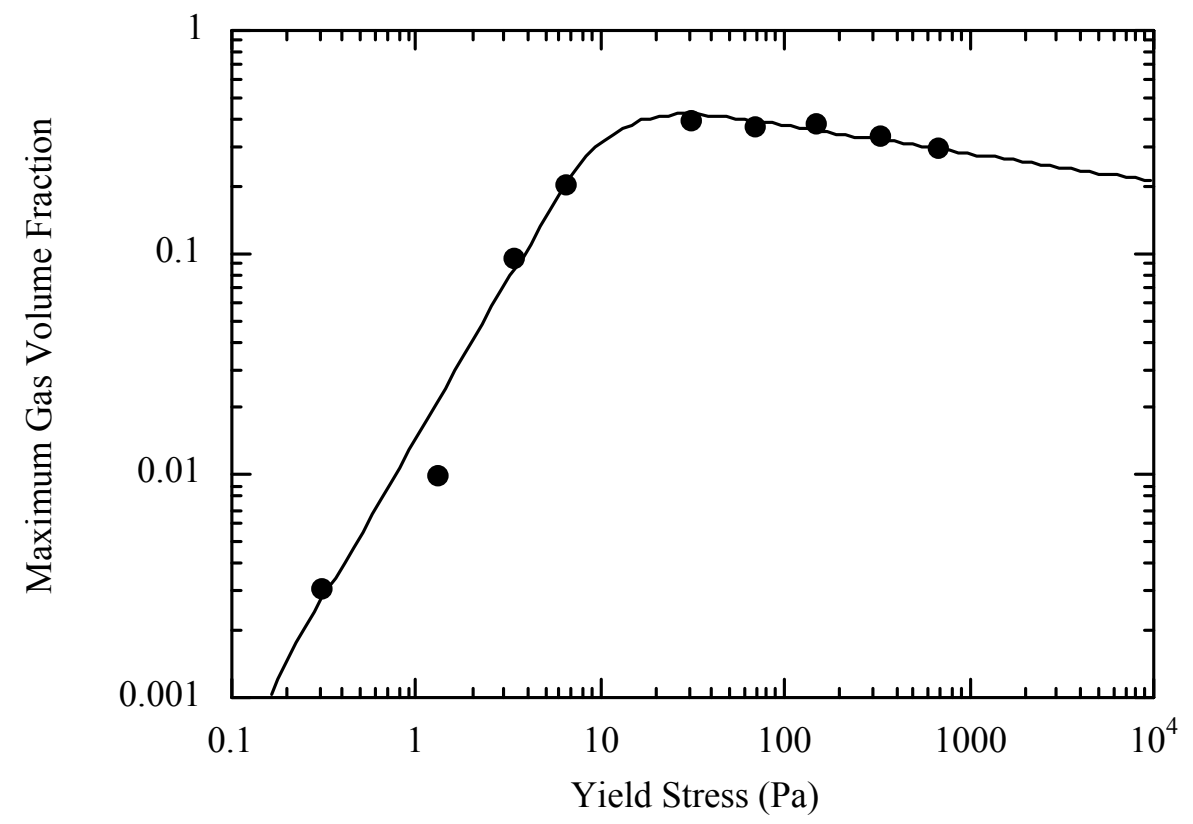

Figure 2.2. Maximum Gas Volume Fraction as a Function of Yield Stress for Bentonite Clay 


\subsection{Maximum Retention for Bubbles Retained by Capillary Forces}

Figure 2.3 shows the maximum retention reported by Gauglitz et al. (1996) for columns containing glass beads in a series of tests wherein each test used a different bead size. For these tests, most of the column had bubbles retained by a capillary force mechanism, and the bubbles occupied the pore space between the beads. The maximum void fraction for bubbles in this regime is generally less than that for bubbles retained by the strength of the material. Specifically, the peak value of the maximum gas retention in Figure 2.2 is about $40 \%$, while the highest value for bubbles retained by capillary forces is about $20 \%$, as shown in Figure 2.3.

The data in Figure 2.3 provide a basis for estimating the maximum gas retention in K Basin material for the region of the material where bubbles are retained by capillary forces. In Section 3.2, results are shown for the fraction of the material in an LDC that has sufficient lithostatic load to cause pore-filling bubbles.

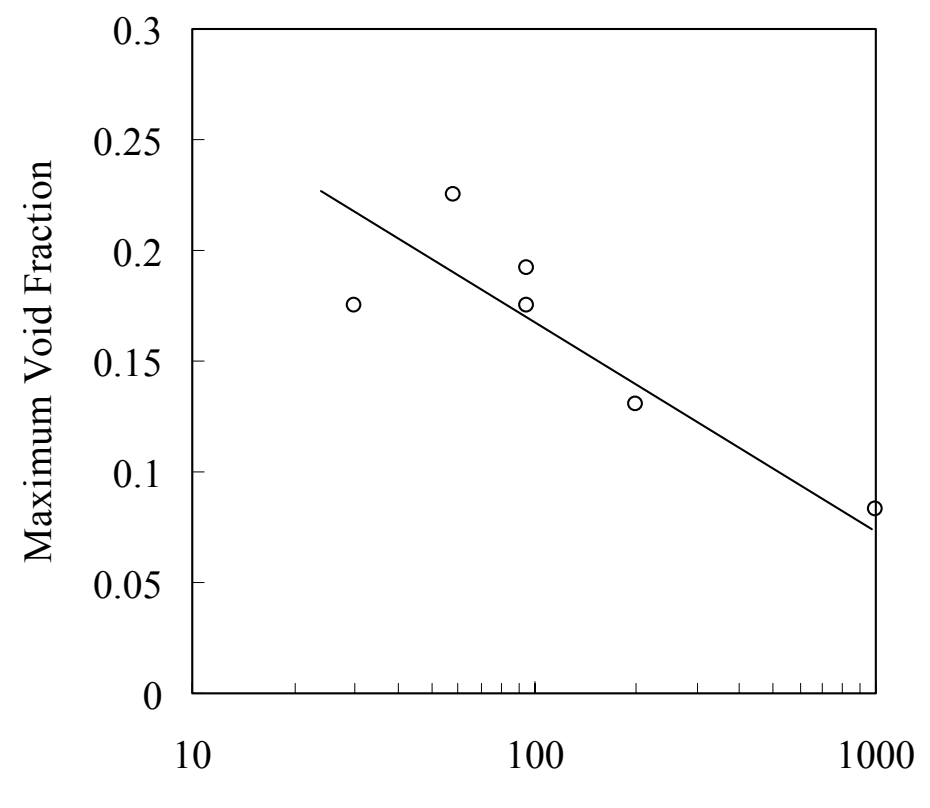

Nominal Bead Size, microns

Figure 2.3. Effect of Particle Diameter on Maximum Gas Fraction 


\subsection{Gas-Bubble Retention Estimates for K Basin Material in LDCs}

This section describes the methodology employed to determine an upper bound on maximum gas volume retention expected in an LDC based on a probabilistic approach. The degree of bubble retention in sludge strongly depends on its yield stress, as evidenced from previous laboratory experiments on gas retention in simulants made of bentonite clay (see Figure 2.2) and glass beads (see Figure 2.3). Therefore, the starting point in this analysis assumes that maximum gas retention data for bentonite clay simulants provide a conservative estimate of bubble retention behavior in K Basin sludge material. Because it is expected that LDCs will be filled in stages that will lead to a stratified arrangement of sludge layers with different average yield stress and thus different degrees of bubble retention, a calculation was performed to estimate the probability of maximum gas retention based on a random selection of $\mathrm{K}$ Basin sludge batches that could originate from various locations within the K Basin pools.

\subsection{Maximum Retention Assuming Random Layers and the Waste Strength Retention Mechanism}

Yield stress measurements of K Basin sludge have been carried out since 1995. A summary of the average values of yield stress from several samples from the $\mathrm{K}$ Basins is shown in Table 3.1 (for a detailed description of yield stress data, refer to Terrones and Gauglitz 2002). Figure 3.1 plots the cumulative probability distribution of yield stress measurements for K Basin samples. The 50th and 95th percentiles for yield stresses are 475 and $5420 \mathrm{~Pa}$, respectively. From these data, a maximum gas volume fraction retained in $\mathrm{K}$ Basin sludge material can be estimated from the curve fit of maximum gas fraction retained in bentonite as a function of yield stress (Figure 3.2). From these data, the 50th and 95th percentiles of the maximum gas volume fractions retained estimates are 0.29 and 0.41 , respectively. Table 3.1 contains all the available yield stress data to-date. The corresponding gas fraction estimates (third column of Table 3.1) will be used in the probabilistic determination of the maximum percentage of retained gas in the K Basins.

An overly conservative, worst-case estimate of the gas fraction is given by the 95th percentile. However, the LDC will contain $\mathrm{K}$ Basin material from a number of different locations, not just from that with the highest void fraction. A reasonable estimate could be given by the 50th percentile void fraction. However, to provide a more meaningful estimate of the void fraction, one must consider the arrangement of $\mathrm{K}$ Basin sludge resulting from the filling process of the LDCs. In practice, this process is achieved by randomly selecting batches from different locations, and thus different gas volume fractions, resulting in a layered arrangement in the LDC. A gas volume fraction probability distribution could be inferred from a statistically large number of possible sludge layering configurations with different degrees of gas retention. With a large number of samples, the average will essentially be the 50th percentile. 
Table 3.1. K Basin Yield Stress Data and Maximum Gas Volume Fraction Estimates

\begin{tabular}{|l|c|c||}
\hline \multicolumn{1}{|c|}{ Sample ID } & $\begin{array}{c}\text { Average } \\
\text { Yield Stress } \\
(\mathbf{P a})\end{array}$ & $\begin{array}{c}\text { Maximum Gas } \\
\text { Fraction } \\
\text { Estimate }\end{array}$ \\
\hline KES-M-13 Top & 2.2 & 0.0450 \\
\hline KES-T-20 Top & 0.9 & 0.0130 \\
\hline 96-04 U/L & 95 & 0.376 \\
\hline 96-06 U/M & 200 & 0.343 \\
\hline 96-06 M & 150 & 0.356 \\
\hline 96-06 M/L & 460 & 0.309 \\
\hline 96-06 L & 470 & 0.308 \\
\hline 96-11 U/L & 130 & 0.362 \\
\hline $96-21$ Rec & 35 & 0.418 \\
\hline $96-24$ Rec & 25 & 0.418 \\
\hline KC-2/3 M250 & 280 & 0.329 \\
\hline KC-4 P250 & 2800 & 0.246 \\
\hline KC-4 M250 & 300 & 0.326 \\
\hline KC-5 P250 & 2700 & 0.247 \\
\hline KC-5 M250 & 270 & 0.330 \\
\hline FE-3 & 760 & 0.290 \\
\hline FE-3 & 920 & 0.283 \\
\hline FE-3 & 240 & 0.335 \\
\hline FE-5 & 1100 & 0.277 \\
\hline FE-5 & 1800 & 0.260 \\
\hline FE-5 & 4000 & 0.235 \\
\hline KC-4 & 480 & 0.307 \\
\hline KC-4 & 330 & 0.322 \\
\hline KC-4 & 400 & 0.314 \\
\hline KC-5 & 1100 & 0.277 \\
\hline KC-5 & 1600 & 0.264 \\
\hline KC-5 & 1000 & 0.280 \\
\hline KC-2/3 & 5700 & 0.225 \\
\hline KC-2/3 & 4600 & 0.231 \\
\hline KC-2/3 & 8200 & 0.215 \\
\hline SNF + Sludge & 740 & 0.291 \\
\hline Composite & 1900 & 0.259 \\
\hline SNF + Sludge \\
Composite & & \\
\hline & & \\
\hline
\end{tabular}




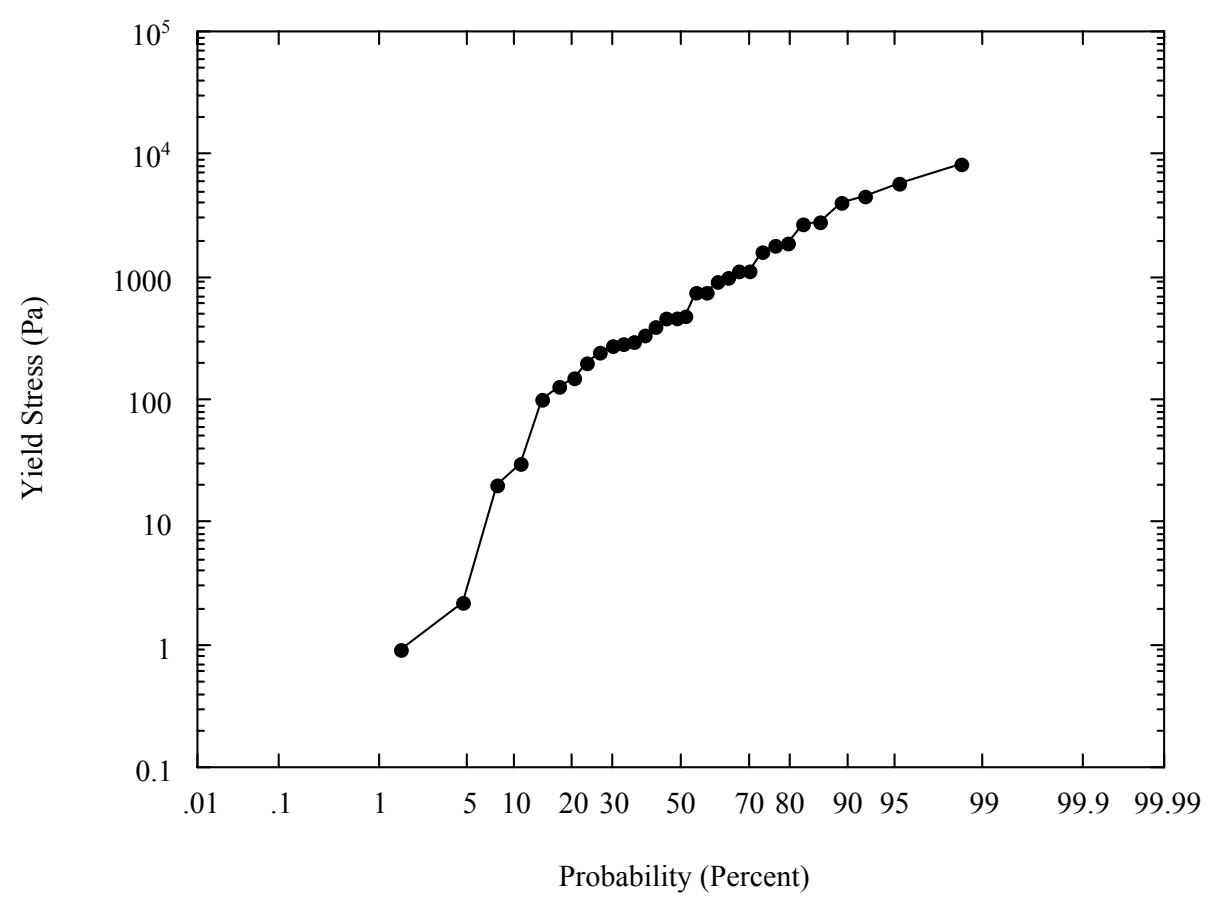

Figure 3.1. Cumulative Probability Distribution of Individual Yield Stress Measurements for K Basin Samples

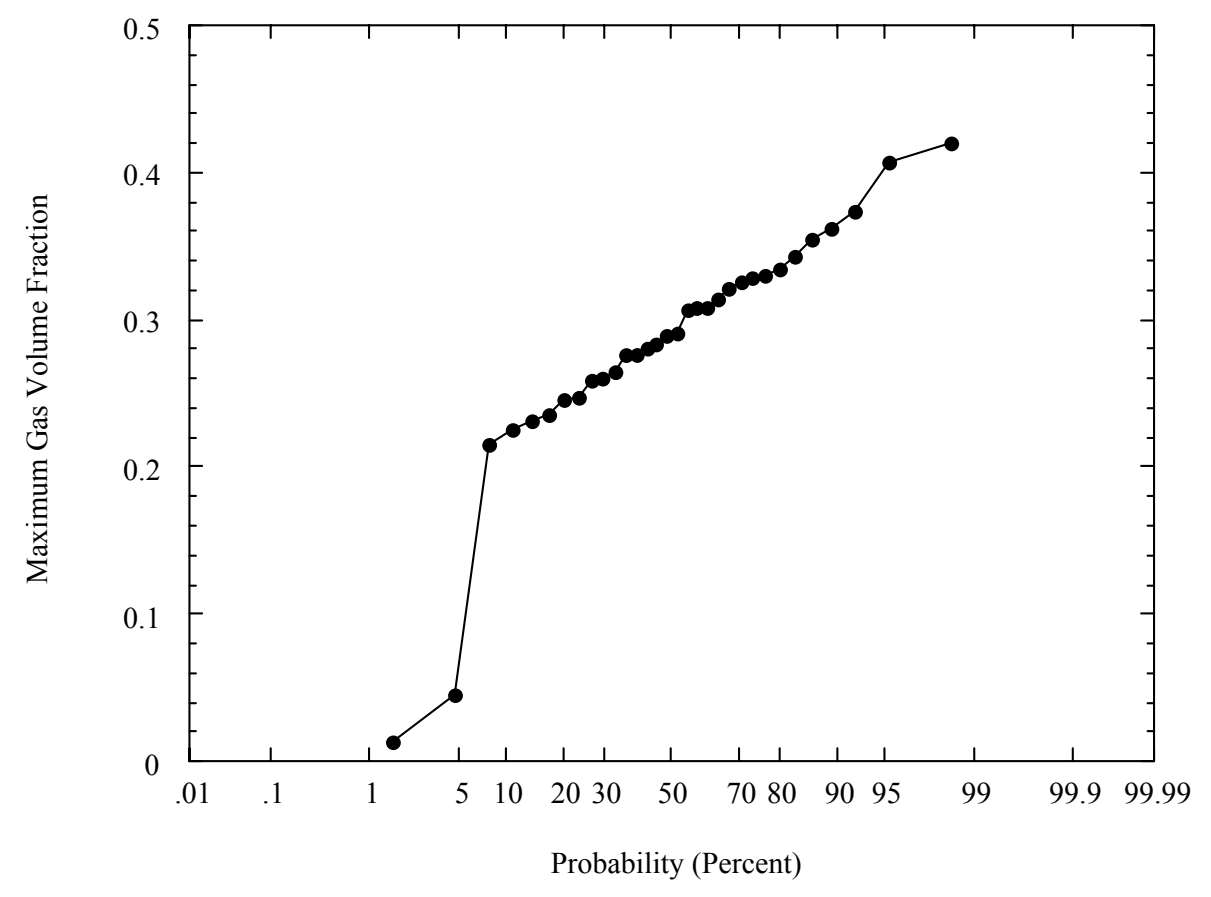

Figure 3.2. Cumulative Probability Distribution of Maximum Gas Volume Fraction Estimates for K Basin Samples 
We assume that the LDC sludge is composed of an equally spaced arrangement of five to ten layers from different batches of material chosen randomly from within the K Basins. Furthermore, each layer is assumed to have the same gas fraction of bed volume, so the total bed gas fraction is calculated by taking the average of the gas fractions from the randomly selected layers. Each of these random selections constitutes a statistical realization. In other words, the contents of an LDC are hypothetically filled by several layers whose maximum volume fraction is randomly selected from the third column of Table 3.1. If the number of layers is few, there will be a few realizations that are higher than the median and a few that are lower. If a large number of realizations are calculated, a distribution is generated for the average gas volume fraction of randomly selected layers. For a five-layer LDC, Figure 3.3 shows the probability distribution obtained from 10,000 realizations. In this case the $95^{\text {th }}$ percentile corresponds to a maximum gas volume fraction of 0.336 , and the median is 0.29 . A maximum gas volume fraction of 0.35 corresponds to the $99^{\text {th }}$ percentile.

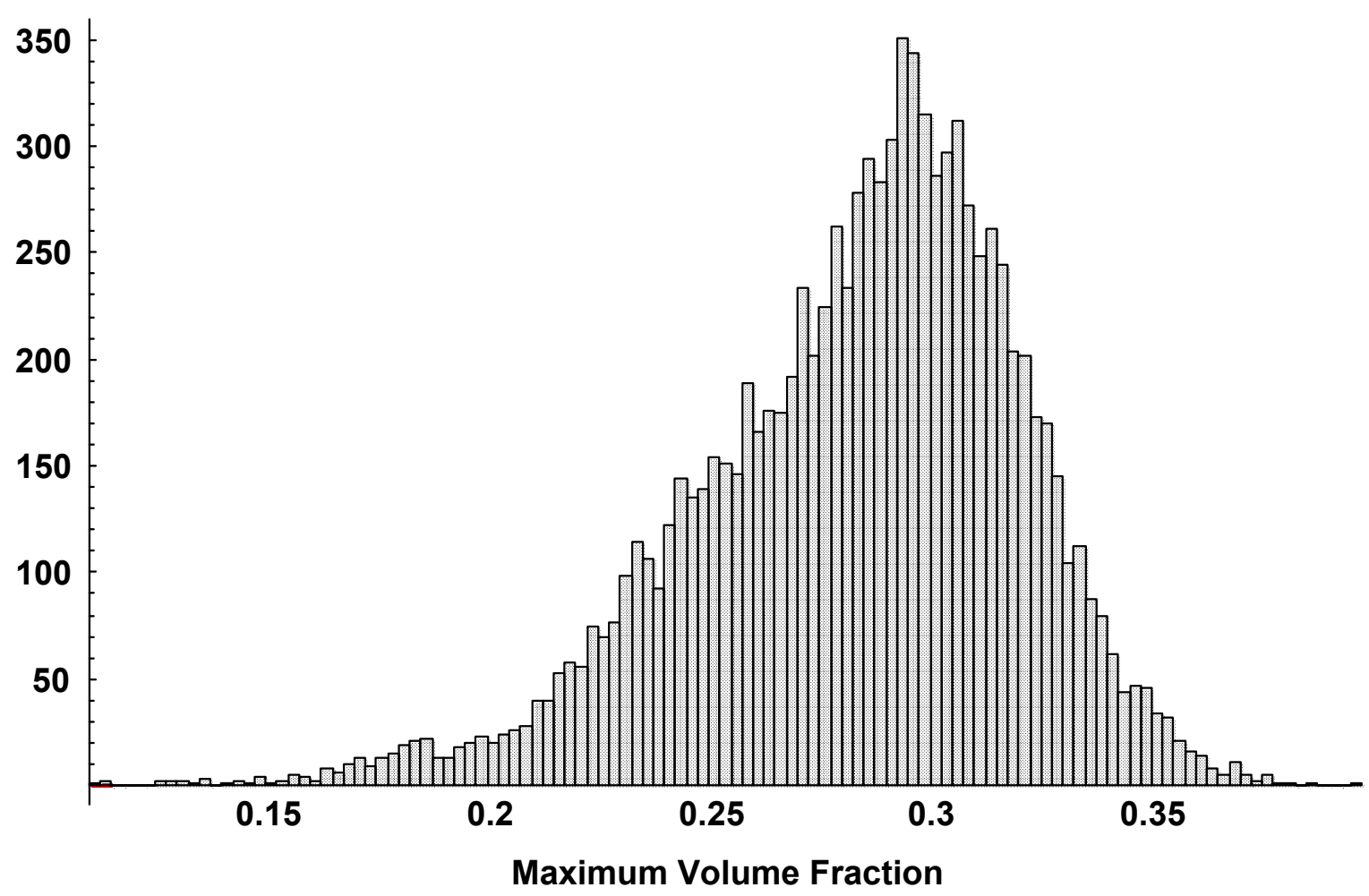

Figure 3.3. Distribution of the Maximum Gas Volume Fraction in an LDC with Five Randomly Selected Layers 
For a 10-layer LDC, Figure 3.4 shows the probability distribution obtained from 10,000 realizations. In this case, the $95^{\text {th }}$ percentile corresponds to a maximum gas volume fraction of 0.32 , and the median is 0.286 . As the number of randomly selected layers increases, the percentiles of maximum gas fraction decrease, as shown in Figure 3.5 (each point in this plot is based on 10,000 realizations).

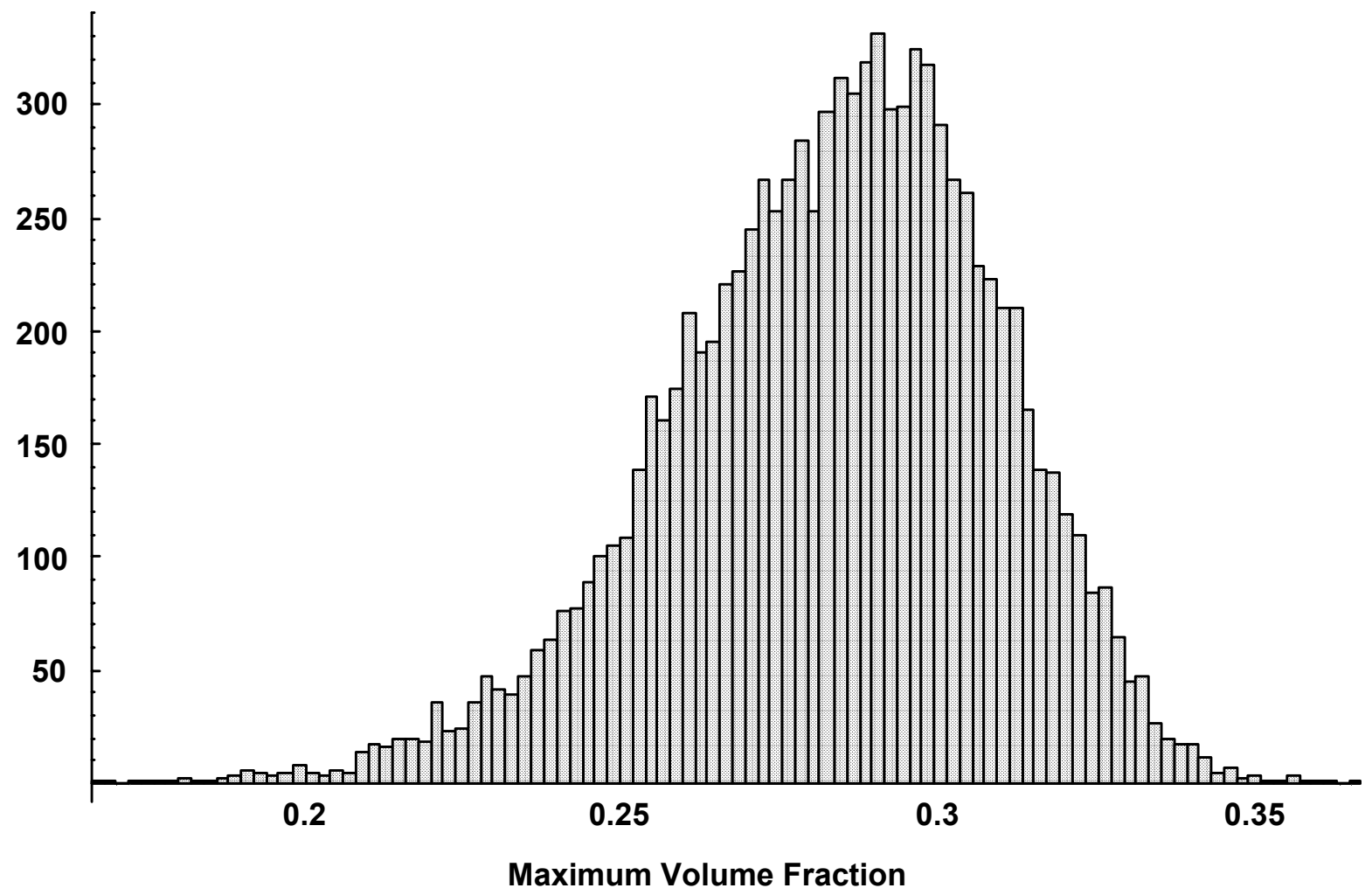

Figure 3.4. Distribution of the Maximum Gas Fraction in an LDC with 10 Randomly Selected Layers 


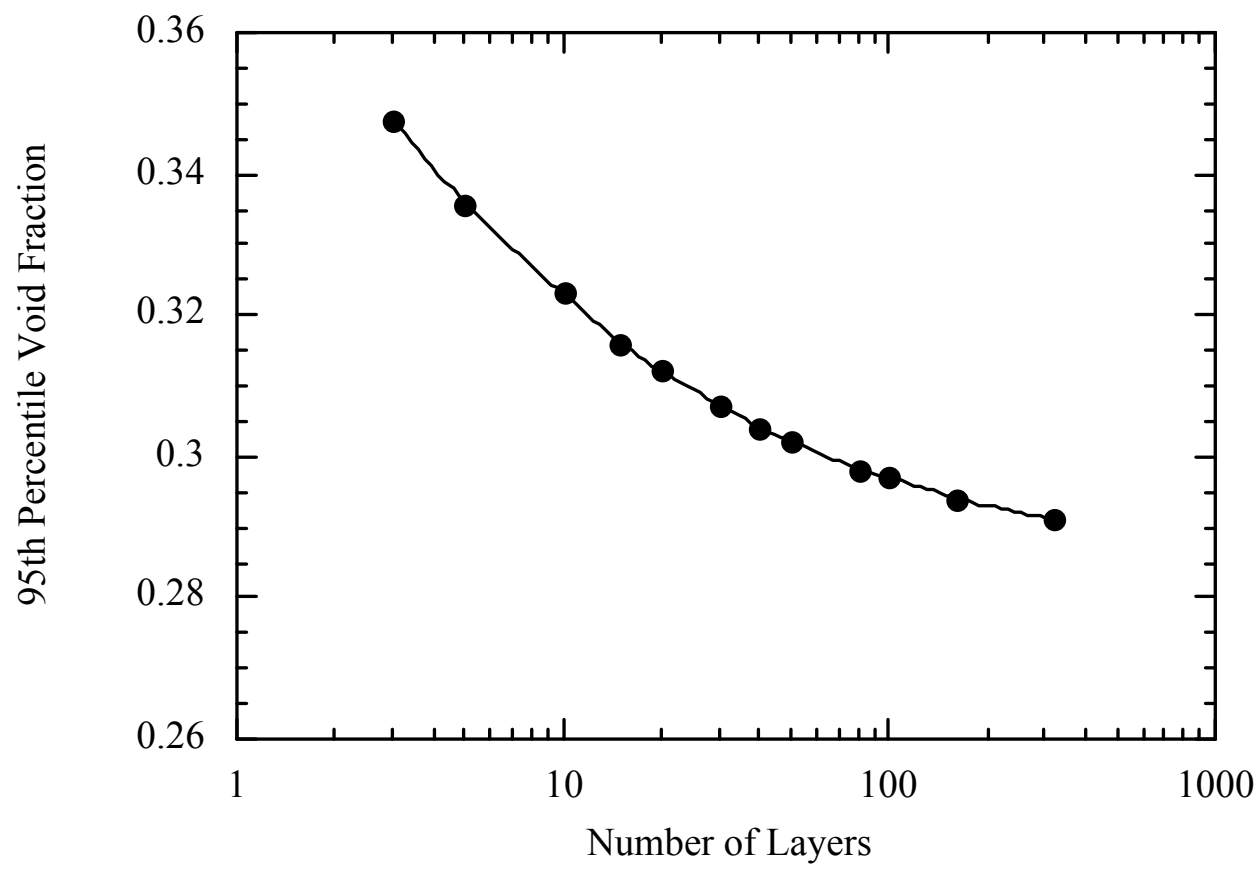

Figure 3.5. 95th Percentile Gas Fraction as a Function of the Number of Randomly Selected Layers for 10,000 Realizations

\subsection{Maximum Retention Assuming Both Capillary Force and Waste Strength Retention Mechanisms}

If a substantial region of the material in an LDC has pore-filling bubbles retained by capillary forces, the maximum retention would approach the values in Figure 2.3, or roughly 20\%. There are two approaches for estimating the transition between pore-filling bubbles and particledisplacing bubbles, hence the fraction of the material having comparatively low retention. Unfortunately, these two approaches give significantly different estimates for the transition. Accordingly, it is not reasonable to predict lower maximum gas retention by accounting for the two regimes of bubble retention. The two estimates of the transition depth are shown below.

Figure 3.6 shows the reported transition depths for beds of glass beads and, in one case, polymethylmethacrylate (PMMA) particles (Gauglitz et al. 1995). The fit of the Bond number scaling (Equation 1) to these data is also shown. When the Bond number equals one, Equation 1 defines the transition depth, $\mathrm{H}_{\mathrm{s}}$, in terms of physical properties and constants. From the viewpoint of making a conservative (highest) estimate of the maximum gas fraction that could occur, the physical properties that give the deepest transition depth are conservative values. Table 3.2 shows the parameter values for estimating the transition depth. These are representative (median) rather than conservative values, and they give a transition depth of $210 \mathrm{~cm}$ based on the Bond number scaling (Equation 1). This is essentially the entire LDC depth. Conservative values would predict an even deeper transition depth. 
Table 3.2. K Basin Sludge Parameter Values for Estimating the Transition Depth

\begin{tabular}{|l|c|l||}
\hline \multicolumn{1}{|c|}{ Parameter } & Value & \multicolumn{1}{c|}{ Reference } \\
\hline Bulk Density & $1.4 \mathrm{~g} / \mathrm{cm}^{3}$ & floor sludge (Table 4-4 of Plys and Pearce 2001) \\
\hline Supernatant Density & $1.0 \mathrm{~g} / \mathrm{cm}^{3}$ & water \\
\hline Particle Diameter & $30 \mathrm{microns}$ & median K East floor (Figure 16 of Bredt et al. 1999) \\
\hline Yield Stress & $500 \mathrm{~Pa}$ & median of all yield stress data (Figure 3.1 of this report) \\
\hline Transition Depth & $210 \mathrm{~cm}$ & from Equation 1 of this report \\
\hline
\end{tabular}

The second approach for estimating the transition depth of $\mathrm{K}$ Basin material is to use the experimental results shown in Figure 3.6 directly. With this approach, the data suggest a transition depth of about $10 \mathrm{~cm}$. Figure 3.6 shows both estimates of the transition depth to allow comparison.

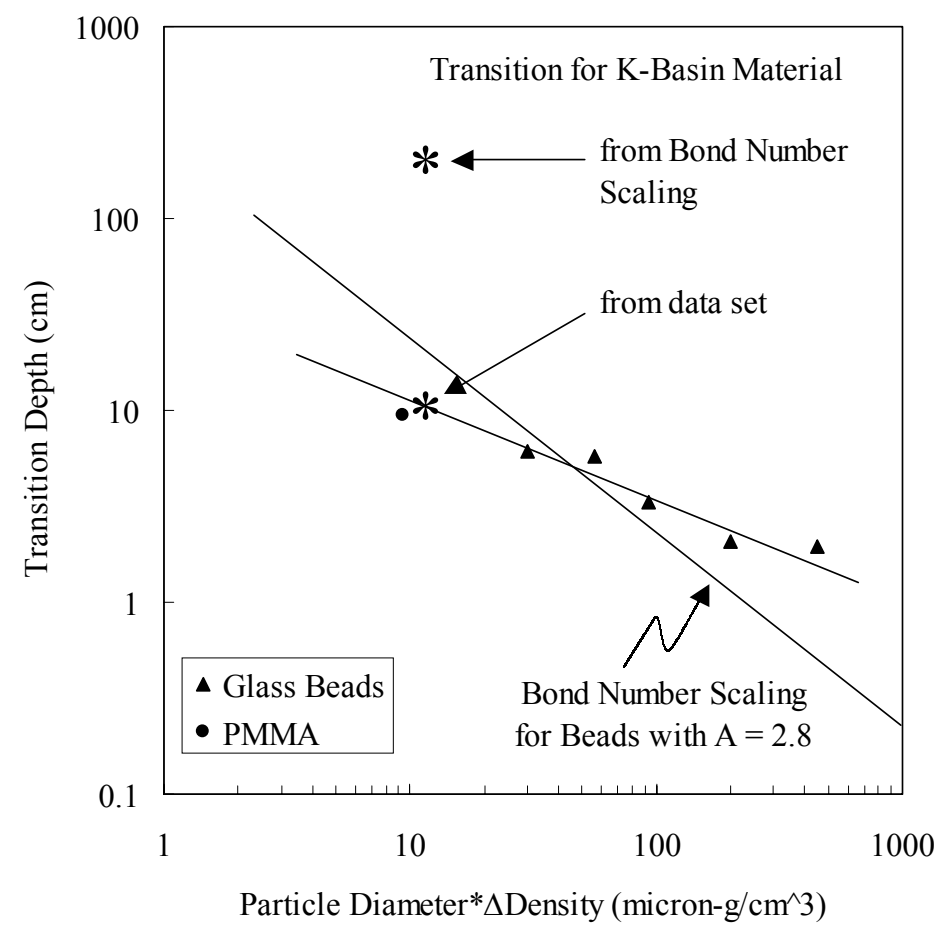

Figure 3.6. Measured Transition Depth Between Particle-Displacing and Pore-Filling Bubbles 
The difference in the two estimates for transition depth is primarily due to a large difference in yield stress between the glass bead and $\mathrm{K}$ Basin materials. In the earlier study (Gauglitz et al. 1995), where the Bond number scaling was fit to the beadpack data, independent yield stress measurements were made for the beakpacks. In developing this fit, a 30-micron beadpack would have a yield stress of about $3000 \mathrm{~Pa}$, which is significantly higher than the median $\mathrm{K}$ Basin yield stress shown in Table 3.2. In the absence of experiments on actual or simulated K Basin materials, the discrepancy in the estimated transition depth is not readily resolved.

The conservative transition depth is the larger of the two estimates, about $210 \mathrm{~cm}$. This is effectively the entire bed depth. In this case, the entire bed has particle-displacing bubbles, and the estimated maximum retention presented in Section 3.1 applies.

\subsection{Gas Retention in Hanford SSTs and DSTs}

The third approach for estimating the potential maximum gas retention in LDCs with $\mathrm{K}$ Basin material is to assume that the gas retention in Hanford DSTs and SSTs represents the behavior of K Basin material in LDCs. The most pertinent Hanford tanks to consider in this approach are those known to generate and retain gas bubbles and for which gas retention and yield stress measurements have been reported.

Figure 3.7 shows the relationship between gas fraction and yield stress where data have been reported for both parameters (Johnson et al. 2001; Hedengren et al. 2001). While the data for bentonite clays were taken from simple, well-defined experiments, the actual tank behavior is much more complicated. This presentation of the tank data is simplistic and mixes average values and individual measurements. Regardless, the primary observation is that the actual tank behavior has gas retention measurements that fall below the bentonite clay data with only one exception. Key differences between actual tank behavior and the simulants are the much larger scale and longer duration of the actual tank situation. This comparison supports an assertion that the bentonite data are conservative.

Figure 3.8 shows the cumulative distribution of the void fraction reported by Johnson et al. (2001) for individual core samples taken from seven SSTs, excluding samples taken from the supernatant liquid. These SSTs and void fractions seem most pertinent to gas retention in $\mathrm{K}$ Basin material, although they do represent the tanks with highest amounts of retained gas. The SST data show that a $35 \%$ gas fraction has been measured and exceeded in a few core samples, but that the probability of exceeding $35 \%$ gas retention was only $5 \%$. These measurements were for individual core samples. There were insufficient data to calculate potential retention in LDCs filled with random layers. 


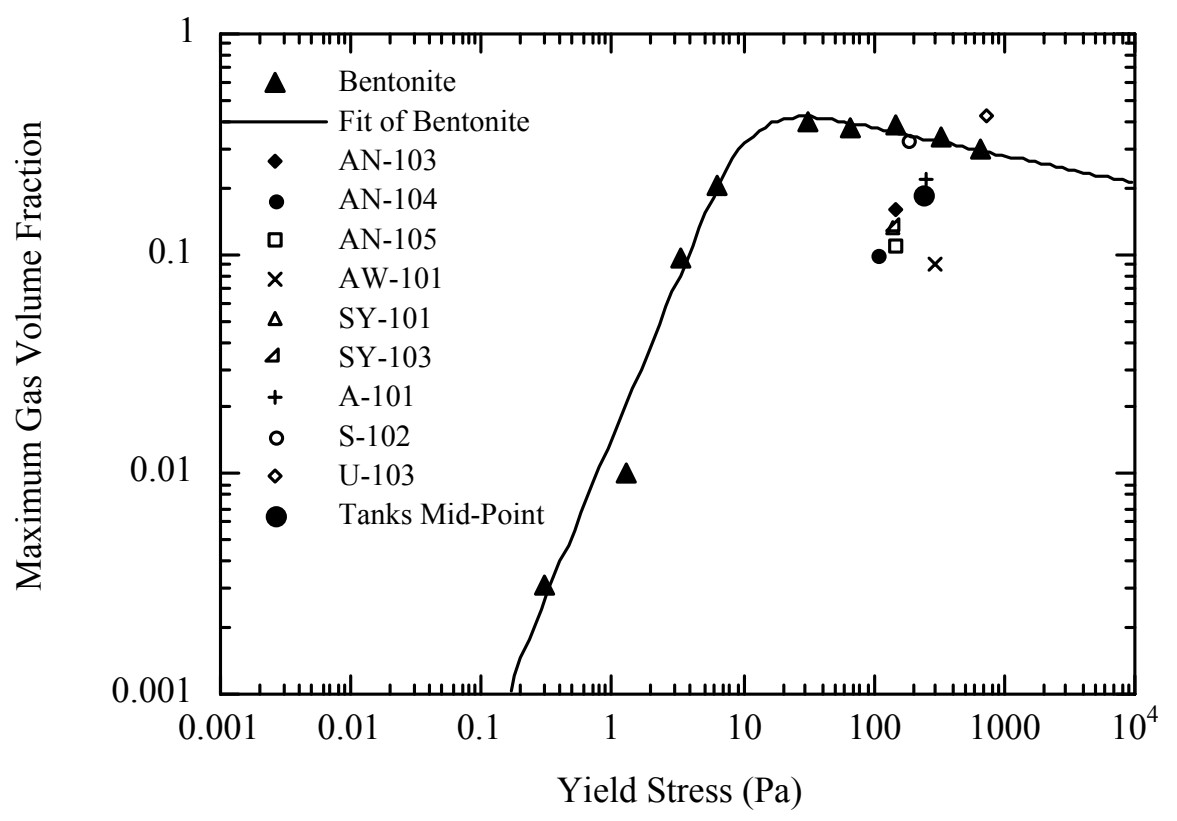

Figure 3.7. Comparison of Bentonite Clay Simulants with Hanford DST and SST Data for the Relationship Between Void Fraction and Yield Stress

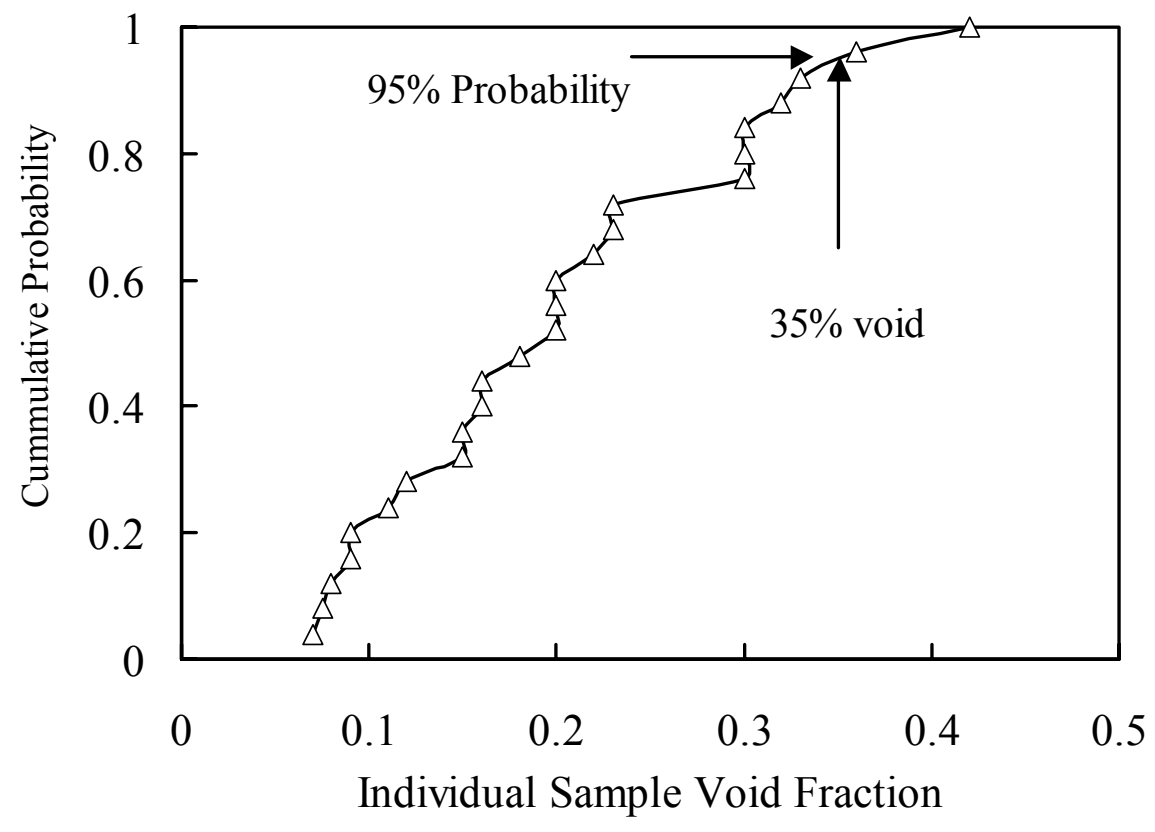

Figure 3.8. Cumulative Probability Distribution of Individual Void Fraction Measurements for Core Samples from A-101, AX-101, S-102, S-111, SX-106, U-103, and U-109 


\subsection{Possible Mechanisms for Lower Gas-Bubble Retention}

While many studies have focused on the physical properties and gas generation behavior of K Basin samples, no specific studies have sought to document mechanisms of gas-bubble retention in K Basin simulants or actual material. Still, during testing for gas generation behavior, video recordings were sometimes made when retained bubbles were observed. Welsh et al. (1992) have described a unique mechanism of bubble release where a narrow pathway is established in the sample. This preferred pathway remains open, and gas bubbles repeatedly move through this pathway. After reviewing the video recordings in the collection held by Paul Bredt, ${ }^{(a)}$ there were no new observations or mechanism of retention or release. Figure 3.9 is an image of bubbles in preferential paths. The image for sample 96-23 was previously documented,${ }^{(b)}$ and the images for samples $96-13$ and 96-08 were obtained from RB Baker. ${ }^{(\mathrm{c})}$

The mechanism of preferential channel formation allows gas release while the overall gas fraction is relatively low. If this mechanism is dominant in the LDCs when filled with K Basin material, then the maximum gas retention could be significantly less than the $35 \%$ estimate based on uniformly distributed gas-generating particles and bubbles.

(a) PR Bredt maintains a library of about 200 videotapes of samples and testing activities for studies conducted in the High-Level Radiochemistry Facility in the 325 Building.

(b) The project report by KL Silvers (PNNL), KW Basin Canister Sludge Sample Analysis, Revision 1, September 16, 1997, presents this image in Figure 1.6. The image shown in Figure 3.9 was recreated form the original video recording with image enhancement.

(c) RB Baker $(\mathrm{FH})$ provided a video print of these bubble images. 


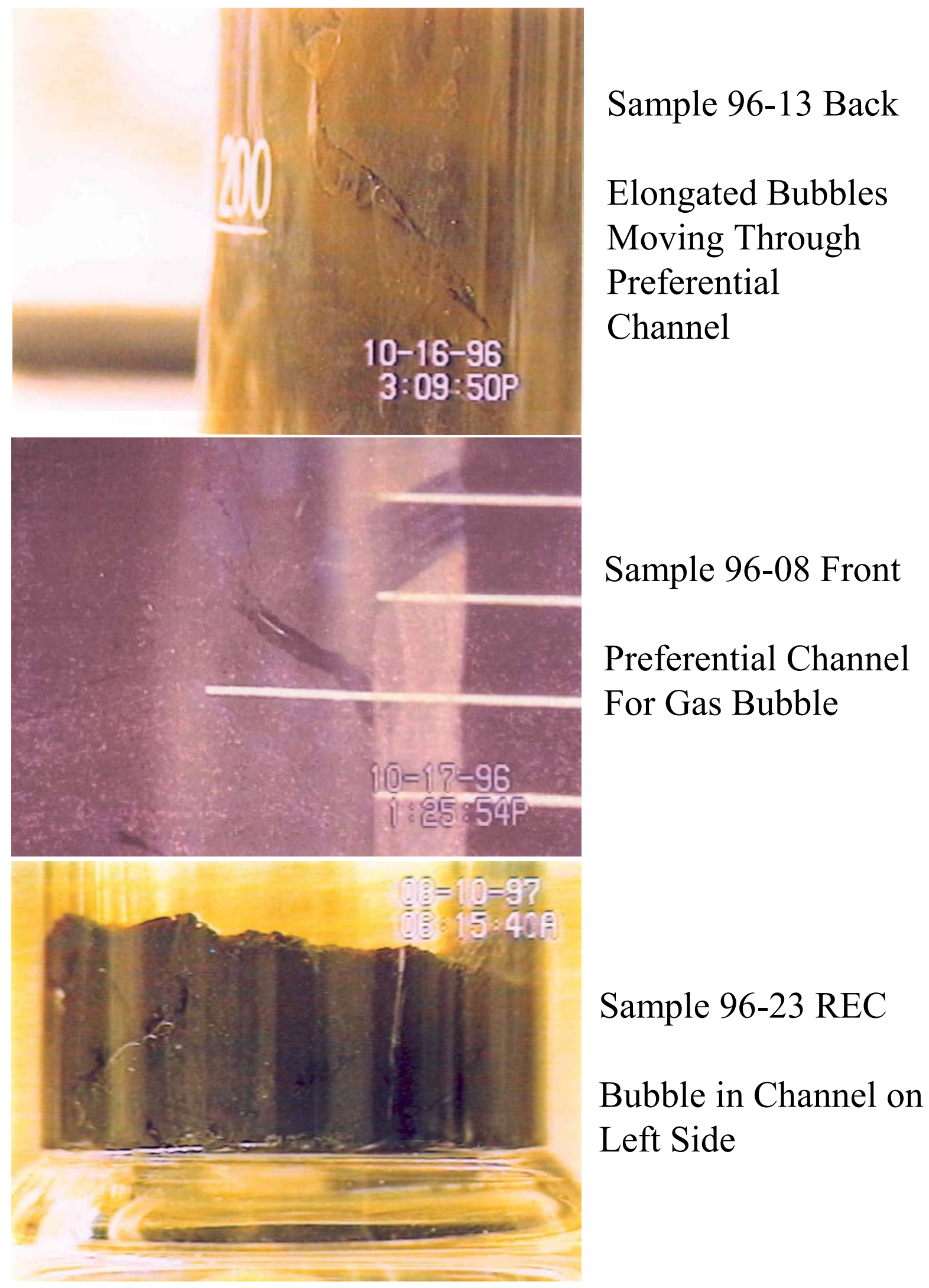

Figure 3.9. Observation of Bubbles in Preferential Channels for Bubble Migration 


\subsection{Discussion and Recommendation for Maximum Gas-Bubble Retention}

Estimates of the maximum gas volume fraction that might occur in $\mathrm{K}$ Basin material stored in LDCs have been determined by three different approaches. The first approach assumed that 1) particle displacing bubbles are retained by the strength of the material, 2) bentonite clay simulants can represent K Basin material, and 3) LDC sludge comprises discrete layers of material with yield stress randomly selected from all available K Basin measurements. The second approach assumed two distinct regimes of bubble retention. In the lower regime, bubbles filled the pores between the particles, and in an upper regime bubbles displaced the particles. The total gas retention in the LDC was a combination of these two bounding regimes of retention. The third approach was based on an estimate of gas retention in Hanford DSTs and SSTs that are known to retain significant quantities of gas.

Based on the existing data and understanding of K Basin material and the LDCs, the first approach seems most appropriate. In addition, after reviewing many video recordings of laboratory testing on $\mathrm{K}$ Basin material, the bentonite clay simulant appears more representative than the glass bead simulant. The primary deficiency in bentonite clay data for maximum retention, as shown in Figure 2.2, is that the gas bubbles were created via decomposition of a small amount of hydrogen peroxide in solution. In actual $\mathrm{K}$ Basin material, gas bubbles originate at individual particles of metallic uranium. This difference in bubble creation potentially explains the observed formation of preferential channels shown in Figure 3.9 for $\mathrm{K}$ Basin material. Regardless of this deficiency, in the absence of bubble retention measurement in $\mathrm{K}$ Basin material, the bentonite clay retention data are a reasonable upper bound.

The results presented in Section 3.1 show that an LDC filled with at least five layers has a $99 \%$ probability of having a maximum gas retention level of less than $35 \%$, assuming the retained bubbles are uniformly distributed. Accordingly, until testing can be conducted to support a lower estimate, this work recommends that $35 \%$ void be assumed to represent the maximum gas volume fraction that could be achieved in an LDC.

The second approach does not change the estimate of $35 \%$ retention because the predicted location of the transition is deeper than the bed. This predicted location, however, is based on a value for yield stress that is much less than beadpacks with similar particle-size material. In simulants composed of glass beads, a transition depth of $\sim 10 \mathrm{~cm}$ has been reported for glass beads having the same median diameter as the $\mathrm{K}$ Basin material. If this shallow transition depth were to occur, the maximum retention would be close to $20 \%$ void, as described in Section 3.2. However, in the absence of testing on $\mathrm{K}$ Basin simulant or actual material, this lower retention estimate is not recommended.

For the third approach, gas retention in the SSTs that are known to generate and retain gas seems most relevant to the behavior of K Basin material in LDCs. The SST data show that 35\% 
gas fraction has been measured and exceeded in a few core samples but that the probability of exceeding 35\% gas retention was only 5\%. These measurements were for individual core samples. Insufficient data were available to calculate potential retention in LDCs filled with random layers based on these data.

In conclusion, $35 \%$ gas retention represents the maximum retention level that might occur in $\mathrm{K}$ Basin material stored in LDCs. This estimate is substantiated by the results of the analysis described in this report and based on literature data from a variety of laboratory studies and actual systems. 


\subsection{References}

Baker RB, BJ Makenas, and JA Pottmeyer. 2000. Observations of K Basins Sludge Behavior in Relation to Sludge Container Design and Storage at T Plant. HNF-6705 Rev. 0, Fluor Hanford, Inc., Richland, Washington.

Bredt PR, SM Tingey, and EH Shade. 1995. The Effect of Dilution on the Gas Retention Behavior of Tank 241-SY-101 Waste. PNL-10781, Pacific Northwest Laboratory, Richland, Washington.

Bredt PR, and SM Tingey. 1996. The Effect of Dilution on the Gas Retention Behavior of Tank 241-SY-103 Waste. PNNL-10893, Pacific Northwest National Laboratory, Richland, Washington.

Bredt PR, CH Delegard, AJ Schmidt, and KL Silvers. 1999. Testing and Analysis of Consolidated Sludge Sample from 105 K East Basin Floor and Canisters. PNNL-13341, Pacific Northwest National Laboratory, Richland, Washington.

Bryan SA, CH Delegard, AJ Schmidt, RL Sell, KL Silvers, SR Gano, and BM Thornton. 2001. Gas Generation from K East Basin Sludges-Series II Testing. PNNL-13446, Pacific Northwest National Laboratory, Richland, Washington.

Chhabra RP. 1993. Bubbles, Drops, and Particles in Non-Newtonian Fluids. CRC Press, Boca Raton, Florida.

Gauglitz PA, LA Mahoney, DP Mendoza, and MC Miller. 1994. Mechanisms of Gas Bubble Retention. PNL-10120, Pacific Northwest Laboratory, Richland, Washington.

Gauglitz PA, SD Rassat, MR Powell, RR Shah, and LA Mahoney. 1995. Gas Bubble Retention and its Effect on Waste Properties: Retention Mechanisms, Viscosity, and Tensile and Shear Strength. PNL-10740, Pacific Northwest Laboratory, Richland, Washington.

Gauglitz PA, SD Rassat, PR Bredt, JH Konynenbelt, SM Tingey, and DP Mendoza. 1996. Mechanisms of Gas Bubble Retention and Release: Results for Hanford Waste Tanks 241-S-102 and 241-SY-103 and Single-Shell Tank Simulants. PNNL-11298, Pacific Northwest National Laboratory, Richland, Washington.

Gauglitz PA, G Terrones, SJ Muller, MM Denn, and WR Rossen. 2001. Mechanics of Bubbles in Sludges and Slurries: Final Report for U.S. Department of Energy. PNNL-13748, Pacific Northwest National Laboratory, Richland, Washington.

Hedengren DC, TA Hu, MA Kufahl, DJ McCain, CW Stewart, JL Huckaby, LA Mahoney, and KG Rappe. 2001. Data and Observations of Single-Shell Flammable Gas Watch List Tank Behavior. RPP-7249, CH2M HILL Hanford Group, Inc., and Pacific Northwest National Laboratory, Richland, Washington.

Johnson AB. 1995. K Basin Corrosion Program Report. WHC-EP-0877, Westinghouse Hanford Company, Richland, Washington. 
Johnson GD, WB Barton, JW Brothers, SA Bryan, PA Gauglitz, RC Hill, LR Pederson, CW Stewart, and LM Stock. 1997. Flammable Gas Project Topical Report. HNF-SP-1193, Rev. 2, Richland, Washington.

Johnson GD, DC Hedengren, JM Grigsby, CW Stewart, JJ Zach, and LM Stock. 2001. Flammable Gas Safety Issue Resolution. RPP-7771 Rev. 0-A, CH2M HILL Hanford Group, Richland, Washington.

Makenas BJ, TL Welsh, RB Baker, DR Hansen, and GR Golcar. 1996. Analysis of Sludge from Hanford K East Basin Floor and Weasel Pit. WHC-SP-1182, Westinghouse Hanford Company, Richland, Washington.

Makenas BJ, TL Welsh, RB Baker, EW Hoppe, AJ Schmidt, J Abrefah, JM Tingey, PR Bredt, and GR Golcar. 1997. Analysis of Sludge from Hanford K East Basin Canisters. HNF-SP1201, Duke Engineering \& Services Hanford, Inc., Richland, Washington.

Makenas BJ, TL Welsh, RB Baker, GR Golcar, PR Bredt, AJ Schmidt, and JM Tingey. 1998. Analysis of Sludge from Hanford K West Basin Canisters. HNF-1728 Rev. 0, Fluor Daniel Hanford, Richland, Washington.

Makenas BJ, TL Welsh, PR Bredt, GR Golcar, AJ Schmidt, KL Silvers, JM Tingey, AH Zacher, and RB Baker. 1999. Analysis of Internal Sludge and Cladding Coatings from N-Reactor Fuel Stored in Hanford K Basins. HNF-3589 Rev. 0, Fluor Daniel Hanford, Richland, Washington.

Pearce KL. 2001. 105-K Basin Material Design Basis Feed Description for Spent Nuclear Fuel Project Facilities, Volume 2, Sludge. HNF-SD-SNF-TI-009 Rev. 4, Fluor Hanford, Inc., Richland, Washington.

Plys MG and KL Pearce. 2001. Supporting Basis for Spent Nuclear Fuel Project Sludge Technical Databook. SNF-7765 Rev. 0, Fluor Hanford, Richland, Washington.

Rassat SD, PA Gauglitz, PR Bredt, LA Mahoney, SV Forbes, and SM Tingey. 1997. Mechanisms of Gas Bubble Retention and Release: Experimental Results for Hanford Waste Tanks 241-AW-101 and 241-AN-103. PNNL-11642, Pacific Northwest National Laboratory, Richland, Washington.

Rassat SD, SM Caley, PR Bredt, PA Gauglitz, DE Rinehart, and SV Forbes. 1998. Mechanisms of Gas Bubble Retention and Release: Experimental Results for Hanford Single Shell Waste Tanks 241-A-101, 241-S-106, and 241-U-103. PNNL-11981, Pacific Northwest National Laboratory, Richland, Washington.

Rassat SD, PA Gauglitz, SM Caley, LA Mahoney, and DP Mendoza. 1999. A Discussion of SY-101 Crust Gas Retention and Release Mechanisms. PNNL-12092, Pacific Northwest National Laboratory, Richland, Washington.

Schmidt AJ and $\mathrm{CH}$ Delegard. 2002. Assessment of $K$ Basin Sludge Volume Expansion Resulting from Uranium Corrosion During Storage. PNNL-13786, Pacific Northwest National Laboratory, Richland, WA. 
Stewart CW, ME Brewster, PA Gauglitz, LA Mahoney, PA Meyer, KP Recknagle, and HC Reed. 1996. Gas Retention and Release Behavior in Hanford Single-Shell Tanks. PNNL11391, Pacific Northwest National Laboratory, Richland, Washington.

Terrones G and PA Gauglitz. 2002. "Vessel-Spanning Bubble Formation in K Basin Sludge Stored in Large Diameter Containers." PNNL-13805, Pacific Northwest National Laboratory, Richland, Washington.

Walker DD, CL Crawford, and NE Bibler. 1994. "Radiolytic Bubble Formation and Level Changes in Simulated High-Level Waste Salts and Sludges-Application to HLW Storage Tanks, Proceedings of Waste Management 1994, Tucson, Arizona, pp. 393-396.

Welsh TL, RB Baker, EW Hoppe, AJ Schmidt, J Abrefah, JM Tingey, PR Bredt, and GR Golcar. Analysis of Sludge from Hanford K East Basin Canisters. HNF-SP-1201, Duke Engineering and Services Hanford, Inc., Richland, Washington.

Wheeler SJ. 1990. "Movement of Large Gas Bubbles in Unsaturated Fine-Grained Sediments." Marine Geotechnology, Vol. 9, pp. 113-129. 
PNNL-13893

\section{Distribution}

No. of

Copies

Offsite

G. L. Dunford

AEM CONSULTING

2417 Mark Avenue

Richland, Washington 99352

2 Fauske and Associates, Inc.

$16 \mathrm{~W} 070$ West $83^{\text {rd }} \mathrm{St}$

Burr Ridge, IL 60521

Attn: M. G. Plys

M. Epstein

3 Polestar Applied Technology, Inc.

601 Williams Blvd

Suite 2A

Richland, Washington 99352

Attn: P. Loscoe

E. L. Fuller

E. N. Dodd

J. E. Swenson

Xwest Group, Inc .

1835 Terminal Drive

Richland, Washington 99352

\section{Onsite}

25 Fluor Hanford

W. S. Ayers

T3-28

R. B. Baker

A. E. Bridges

W. Coulter

J. F. Cox

B. A. Crea
L0-30

$\mathrm{X} 3-85$

H5-24

X3-85

$\mathrm{X} 4-01$
No. of

Copies

D. R. Duncan

X4-01

E. G. Erpenbeck

L0-30

S. L. Hecht

L6-35

J. J. Irwin

L6-35

D. L. McCall

H1-11

L. J. Olguin

H5-24

C. A. Petersen

L0-30

J. A. Pottmeyer

L0-30

T. J. Ruane

X3-61

W.W. Rutherford

L0-30

K. Sathyanarayana

L6-35

M. J. Schliebe

L6-34

J. P. Sloughter

X4-01

G. A. Sly

$\mathrm{X} 3-85$

FHI File/LB (5)

L6-35

$7 \quad$ Fluor Federal Services

B. E. Hey (5)

X3-79

S. F. Kessler

A0-26

M. G. Piepho

B4-47

26 Pacific Northwest National Laboratory

S. Q. Bennett

K7-90

P. A. Bredt

$\mathrm{P} 7-25$

P. A. Gauglitz (10)

K6-28

W. L. Kuhn

$\mathrm{K} 7-15$

P. A. Meyer

$\mathrm{K} 7-15$

S. D. Rassat

K6-28

A. J. Schmidt

K2-12

K. L. Silvers

K9-08

C. W. Stewart

$\mathrm{K} 7-15$

G. Terrones (5)

$\mathrm{K} 7-15$

T. L. Walton

K9-45

Information Release (2)

K1-06 